\title{
Article \\ Experimental and Numerical Study on the Protective Behavior of Weldox 900 E Steel Plates Impacted by Blunt-Nosed Projectiles
}

\author{
Yahui Shi ${ }^{1,2,3,4}$, Ang Hu ${ }^{5}$, , Taisheng Du ${ }^{2,3,4}$, Xinke Xiao ${ }^{2,3,4, * \mathbb{C}}$ and Bin Jia ${ }^{6}$ \\ 1 School of Civil Engineering, Zhengzhou University, 100 Science Avenue, High-Tech Zone, \\ Zhengzhou 450001, China; Syahui1004@163.com \\ 2 School of Civil Engineering, Nanyang Institute of Technology, 80 Changjiang Road, Wancheng District, \\ Nanyang 473004, China; Dutaisheng@126.com \\ 3 Henan International Joint Laboratory of Dynamics of Impact and Disaster of Engineering Structures, \\ Nanyang Institute of Technology, 80 Changjiang Road, Wancheng District, Nanyang 473004, China \\ 4 Innovative Technology Team of Dynamics of Materials and Structures, Nanyang Institute of Technology, \\ 80 Changjiang Road, Wancheng District, Nanyang 473004, China \\ 5 College of Aeronautical Engineering, Civil Aviation University of China, Dongli District, \\ Tianjin 300300, China; 2019012102@cauc.edu.cn \\ 6 Laboratory of Microstructure Studies and Mechanics of Materials LEM3, Lorraine University, \\ 57-070 Metz, France; jiabin@mail.sdu.edu.cn \\ * Correspondence: xiaoxinke@foxmail.com
}

check for updates

Citation: Shi, Y.; Hu, A.; Du, T.; Xiao, X.; Jia, B. Experimental and Numerical Study on the Protective Behavior of Weldox 900 E Steel Plates Impacted by Blunt-Nosed Projectiles. Metals 2022, 12, 141. https://doi.org/ 10.3390/met12010141

Academic Editor: Riccardo Nobile

Received: 8 November 2021

Accepted: 6 January 2022

Published: 12 January 2022

Publisher's Note: MDPI stays neutral with regard to jurisdictional claims in published maps and institutional affiliations.

Copyright: (c) 2022 by the authors Licensee MDPI, Basel, Switzerland. This article is an open access article distributed under the terms and conditions of the Creative Commons Attribution (CC BY) license (https:// creativecommons.org/licenses/by/ $4.0 /)$.

\begin{abstract}
To demonstrate the importance of incorporating Lode angle into fracture criterion in predicting the penetration resistance of high-strength steel plates, ballistic tests of blunt-nosed projectiles with a diameter of $5.95 \mathrm{~mm}$ impacted $4 \mathrm{~mm}$ thick Weldox $900 \mathrm{E}$ steel plates were conducted. Impacting velocity range was $136.63 \sim 381.42 \mathrm{~m} / \mathrm{s}$. The fracture behavior and the ballistic limit velocities (BLVs) were obtained by fitting the initial-residual velocities of the projectiles. Subsequently, axisymmetric finite element (FE) models parallel to the tests were built by using Abaqus/Explicit software, and the Lode-independent Johnson-Cook (JC) and the Lode-dependent ASCE fracture criterion were incorporated into the finite element model for numerical simulation. Meanwhile, to verify the sensitivity of the mesh size in the numerical simulation, different mesh sizes were used in the shear plug area of the target. It can be found that Weldox $900 \mathrm{E}$ steel has obvious mesh size sensitivity by comparing the experimental results and numerical simulation, and the JC fracture criterion and the ASCE fracture criterion predicted similar BLV for the same mesh size.
\end{abstract}

Keywords: Lode angle; fracture criterion; Weldox 900 E; ballistic limit velocities

\section{Introduction}

Due to the advantages of low price, high specific strength, good resilience, and easy processing, high-strength steels are often used in military and civilian protective structures to resist impact and blast loads. Studies of the ballistic performance of high-strength steels have received extensive attention. In the process of collision with the object of action, metal projectiles or targets often undergo large deformation, as well as fracture damage, and the fracture behavior and mechanism of the target directly influence the protection effect [1-3]. Experimental analysis is often limited due to the complex structural problems involved in the resistance of metals to impact loads, numerical simulations represented by the FE method are currently gaining a lot of applications in the field of ballistics. The ballistic performance of a body armor containing titanium structural inserts was investigated by Zochowski et al. [4] through numerical simulations. The results show that $3 \mathrm{D}$ printed structures made of titanium have excellent potential to be used as bulletproof vests. Børvik et al. [5] performed penetration tests and numerical simulations on $12 \mathrm{~mm}$ thick Weldox $460 \mathrm{E}$ steel targets for the blunt projectile. They found that the ballistic limit velocity(BLV) predicted by Johnson-Cook (JC) fracture criterion was about 
$10 \%$ higher than the test results. Dey et al. [6] found that both predicted comparable BLV by JC and Cockcroft-Latham (CL) fracture criterion. Zhang et al. [7] investigated the penetration resistance of double-layer A3 steel target plates against blunt projectiles impact, through experiments and numerical simulations. The results have shown that the residual velocity predictions given by the numerical simulation were in agreement with the test results. Rodríguez-Millán et al. [8] analyzed the ballistic performance of Inconel 718 using a combination of experiments and numerical simulations. They found that the JC model was able to successfully predict the residual velocity and failure mechanism of the target plate. Additionally, they also found that the warhead angle had a more significant effect on the ballistic performance of the target plate. More successful application instances of numerical simulation methods in the field of ballistics of metal targets can be found in references [9-17].

It can be found that the JC fracture criterion was widely used in the field of ballistics from the above-mentioned published literature, and some reasonable results were obtained. However, because metal targets often experience complex and variable stress states when impacted by the projectile [18-21], the JC fracture criterion does not characterize this behavior well. Some scholars believe that the third invariant (Lode angle) has an important influence on the fracture behavior of some metals [22-27], therefore, the characterization of the fracture behavior needs to use two parameters-stress triaxiality and Lode angle. Recently, Xiao et al. [20] used the Lode-independent modified JC (MJC) fracture criterion and the Lode-dependent modified Mohr-Coulomb (MMC) fracture criterion to predict the ballistic resistance of 2024-T351 aluminum alloy plates when impacted by blunt rigid projectiles. The simulation results have shown that the predicted BLV by MMC fracture criterion was more consistent with the test, while the JC fracture criterion overestimated the BLV of the target. Li et al. [27] proposed a novel dynamic failure criterion related to stress triaxiality and Lode angle, and successfully applied it to the numerical simulation of the ballistic performance of naval steel. Deng et al. [28] investigated the fracture mechanism of 6061-T651 aluminum alloy thick plates using a combined experimental-numerical simulation method, and revealed the value of Lode parameters in predicting the ballistic resistance. Xiao et al. [29] used the Lode-independent JC and the Lode-dependent WenMahmoud (WM) fracture criterion to predict the BLV and fracture behavior of 7075-T651 aluminum target plates under blunt projectile impact. The results have shown that the BLV predicted by the WM was more accurate with the test. Xiao et al. [14] conducted 2024-T351 aluminum alloy Taylor impact tests. The results have shown that the Lode-dependent fracture criterion could reflect the fracture behavior of Taylor rods more accurately. The value of introducing Lode angle into the fracture criterion to predict the fracture behavior of ductile metals was revealed further. However, Xiao et al. [30] conducted ballistic tests of the blunt projectiles impacting the $4 \mathrm{~mm}$ thick Weldox $700 \mathrm{E}$ steel plates. The results have shown that the BLVs predicted by JC and MMC fracture criterion were close, although all overestimate the test result. However, the mechanical test results have shown that fracture locus was significantly Lode-dependent. This phenomenon was attributed to the adiabatic temperature rise during the impact.

Due to the above analysis, the authors speculated that the Lode parameter would have a significant impact on low ductility, and low to medium strength metals in the field of ballistics, but has no obvious value for high-strength and high-ductility metals. However, there are very few reports on the ballistic performance of high-strength and high-ductility steels, so the value of introducing the Lode parameter into the fracture criterion to predict the ballistic performance of such metals needs to be proven. Additionally, it is necessary to further understand the fracture mechanism of high-strength and high-ductility steel targets under the impact of the blunt projectile. In this paper, ballistic tests were conducted on Weldox $900 \mathrm{E}$ high-strength steel plates using blunt projectiles. The 2D axisymmetric FE models parallel to experiments were established in the Abaqus/Explicit software. The Lode-independent JC fracture criterion and the Lode-dependent ASCE fracture criterion were used in the FE model for numerical simulations. The influence mechanism of Lode 
parameters in the fracture of Weldox $900 \mathrm{E}$ high-strength and high-ductility metal targets were revealed.

\section{Experimental Overview and Results}

\subsection{Experimental Set-Up}

The ballistic tests were carried out on a one-stage gas gun in the Nanyang Institute of Technology, Nanyang, China. The one-stage gas gun is mainly composed of a pressurized chamber, launch tube, velocity meter, and impact chamber. The schematic diagram of these devices is shown in Figure 1. To record the complete process of the projectiles impacting the targets during the test, the high-speed camera (Photron FASTCAM SA-Z, Photron, Tokyo, Japan) was adopted with a shooting speed of 60,000 fps.

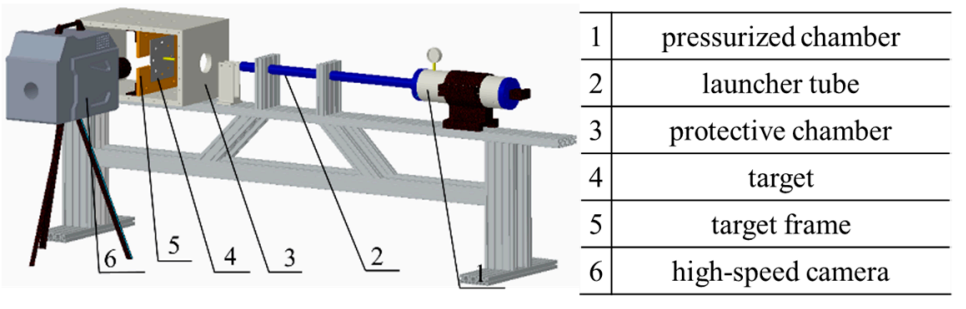

Figure 1. Schematic diagram of one-stage gas gun.

\subsection{Targets and Projectiles}

The $4 \mathrm{~mm}$ thick Weldox $900 \mathrm{E}$ targets were cut from a $70 \mathrm{~mm}$ diameter bar by using Wire Electrical Discharge Machining (WEDM). The projectiles are heat-treated 9CrSi with a nominal hardness of $52 \mathrm{HRC}$. The geometry of target and projectile are shown in Figure 2. Meanwhile, to avoid the boundary effect, $12 \mathrm{M} 3$ bolts were used to fix the targets on the support frame, as shown in Figure 3.

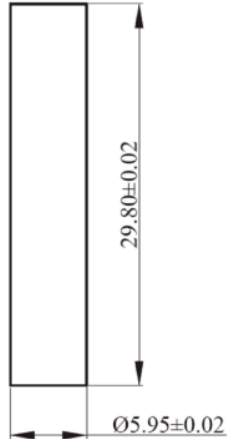

(a)
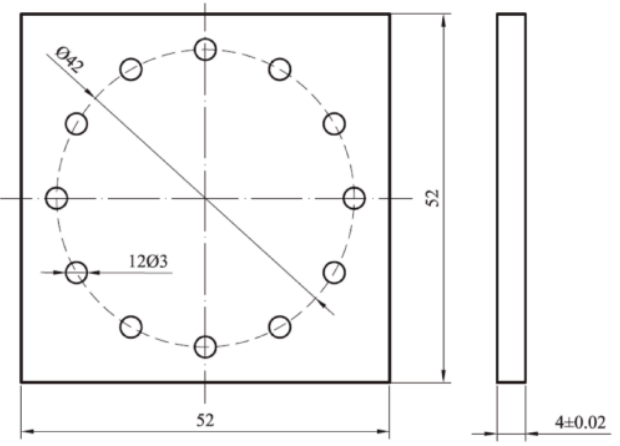

(b)

Figure 2. Projectile and target processing drawing (unit: mm). (a) Projectile. (b) Target.

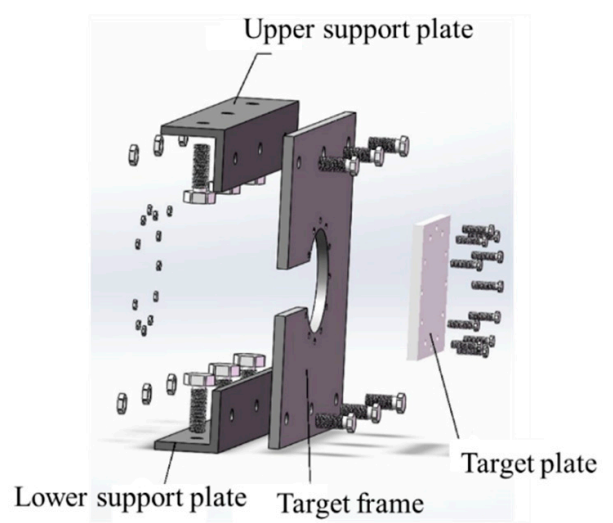

Figure 3. The assembly pattern of target and support frame. 


\subsection{Experimental Results}

In this paper, 15 effective tests with different initial velocities were conducted, with velocity range from 136.63 to $381.42 \mathrm{~m} / \mathrm{s}$, as shown in Table 1 -in which $D$ is diameter, $L$ is length, $m$ is mass, and $V_{0}, V r$ are the initial velocity and residual velocity of the projectile, respectively. It is worth noting that the discrete nature of the material properties, or the inhomogeneity of the organization can lead to residual velocity which is random within a certain range, such as No.4-7, especially near the BLV. However, this does not affect the overall pattern of the initial-residual velocity change.

Table 1. The ballistic test results of Weldox 900 E steel targets.

\begin{tabular}{ccccccc}
\hline No. & $\boldsymbol{D}(\mathbf{m m})$ & $\boldsymbol{L}(\mathbf{m m})$ & $\boldsymbol{m}(\mathbf{g})$ & $V_{\mathbf{0}}(\mathbf{m} / \mathbf{s})$ & $V_{\boldsymbol{r}}(\mathbf{m} / \mathbf{s})$ & Status \\
\hline 1 & 5.94 & 29.82 & 6.39 & 257.23 & 149.13 & $\mathrm{P}$ \\
2 & 5.94 & 29.8 & 6.40 & 236.11 & 128.18 & $\mathrm{P}$ \\
3 & 5.94 & 29.8 & 6.39 & 214.20 & 111.24 & $\mathrm{P}$ \\
4 & 5.93 & 29.81 & 6.39 & 198.99 & 76.63 & $\mathrm{P}$ \\
5 & 5.96 & 29.82 & 6.39 & 193.52 & 81.78 & $\mathrm{P}$ \\
6 & 5.94 & 29.82 & 6.39 & 198.13 & 84.07 & $\mathrm{P}$ \\
7 & 5.93 & 29.81 & 6.39 & 194.46 & 73.64 & $\mathrm{P}$ \\
8 & 5.94 & 29.83 & 6.39 & 186.32 & 64.84 & $\mathrm{P}$ \\
9 & 5.95 & 29.78 & 6.39 & 177.15 & 44.15 & $\mathrm{P}$ \\
10 & 5.94 & 29.8 & 6.39 & 381.42 & 264.23 & $\mathrm{P}$ \\
11 & 5.94 & 29.77 & 6.39 & 136.63 & 0 & $\mathrm{~B}$ \\
12 & 5.95 & 29.79 & 6.39 & 170.31 & 0 & $\mathrm{~B}$ \\
13 & 5.95 & 29.78 & 6.39 & 168.92 & 0 & $\mathrm{~B}$ \\
14 & 5.95 & 29.8 & 6.39 & 172.93 & 0 & $\mathrm{I}$ \\
\hline
\end{tabular}

Note: P—Penetrated; I-Indented; B—Bounced.

According to the Recht-Ipson (RI) model [31] the BLV of the target plate can be obtained by fitting the initial-residual velocity of the projectile, and the RI model is read:

$$
V_{r}=a\left(V_{0}^{p}-V_{b l}^{p}\right)^{1 / p}
$$

where $a$ and $p$ are the model parameters, $V_{b l}$ is the BLV, $a=0.734, p=2.57$, and $V_{b l}=172.93 \mathrm{~m} / \mathrm{s}$, respectively. The fitting results are shown in Figure 4.

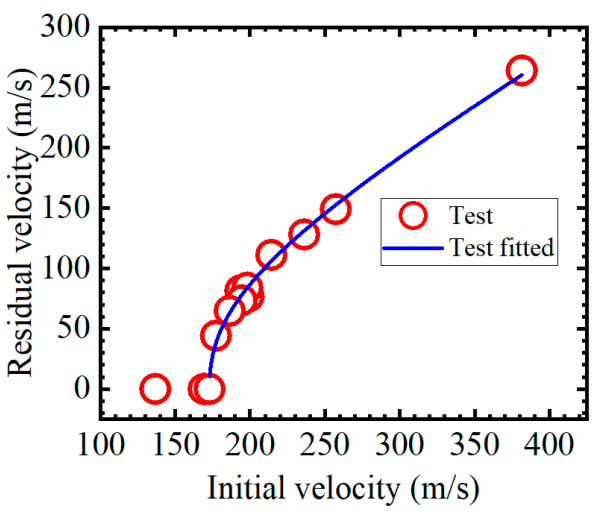

Figure 4. The ballistic test results of Weldox $900 \mathrm{E}$ steel targets.

Figure 5 shows the impact process of the ballistic tests, in which the initial impact velocity of the projectile was slightly below, slightly above, and well above the BLV, respectively. It can be seen from the figure that the projectile bounced, and the rear of the target produced a bulge when the initial velocity was slightly lower than BLV. The projectile penetrated the target and produced a plug when the initial velocity was slightly higher or well above BLV. 


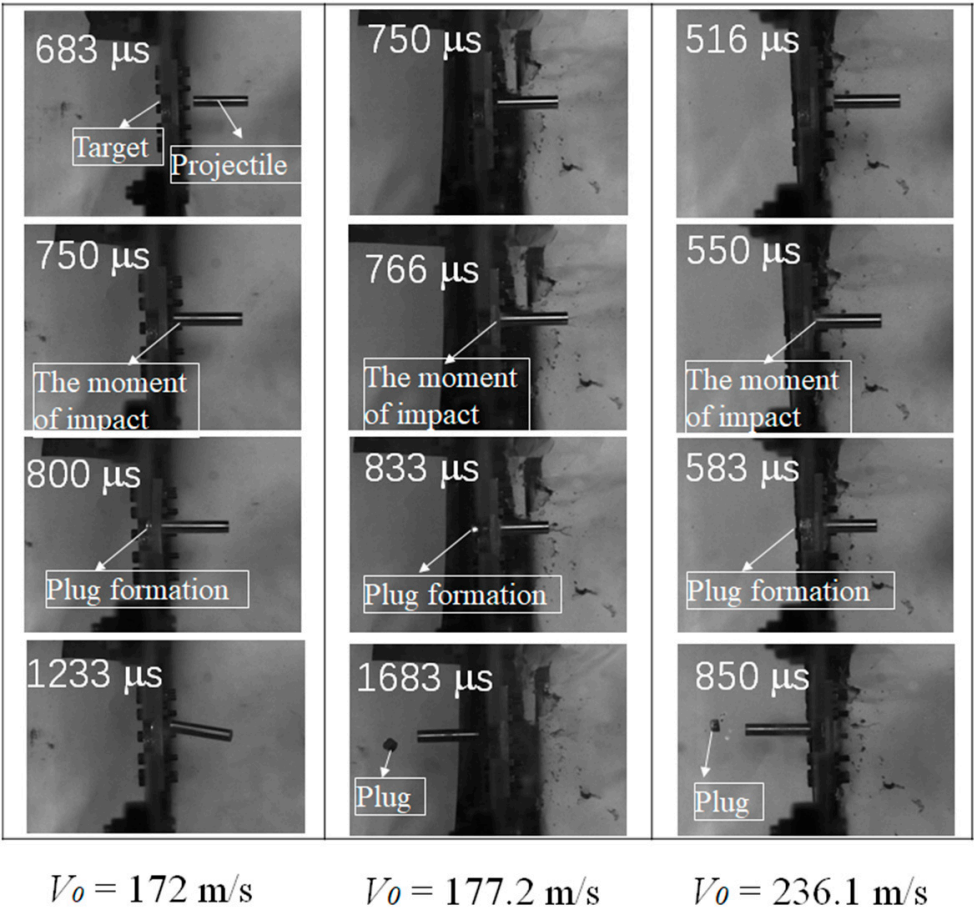

Figure 5. The impact process recorded by the high-speed camera.

In order to further analyze the formation process of the shear plug, the recovered target plates were cut in the thickness direction, and the cracks propagation mechanism under different impact velocities was observed with a microscope, as shown in Figure 6. It can be seen that no cracks were observed in the target plates when the impact velocity is $136.6 \mathrm{~m} / \mathrm{s}$, as shown in Figure 6a. The cracks appeared at the interface between the projectile and the target along the impact direction when the impact velocity is $168.9 \mathrm{~m} / \mathrm{s}$, as shown in Figure 6b. A crack through the target appeared at the corner part of the projectile indentation on the target when the impact velocity was $170.3 \mathrm{~m} / \mathrm{s}$, and a discontinuous crack along the thickness direction appeared at the corner part of the projectile indentation on the right side of the target, as shown in Figure $6 c, d$. This may be caused by uneven resistance during the impact. 

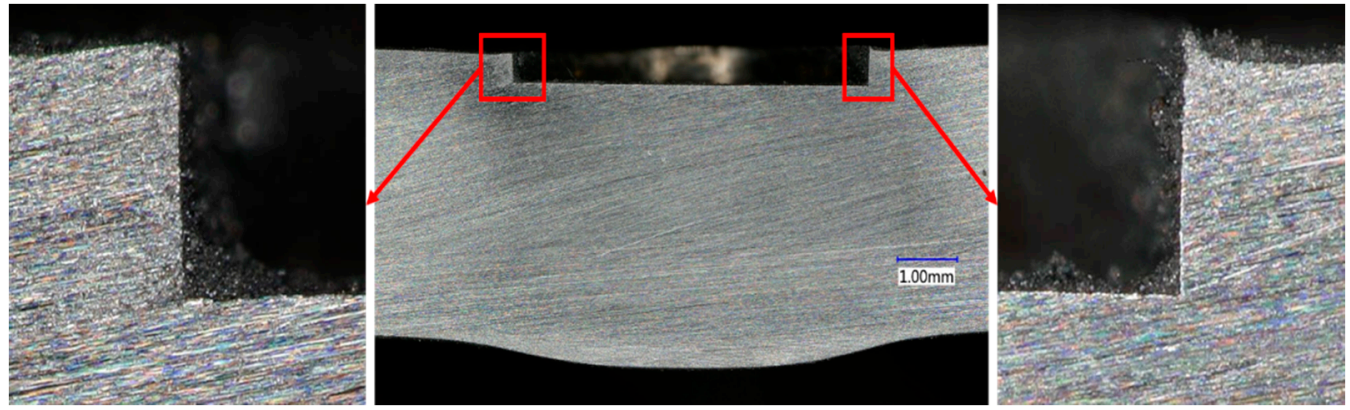

(a)
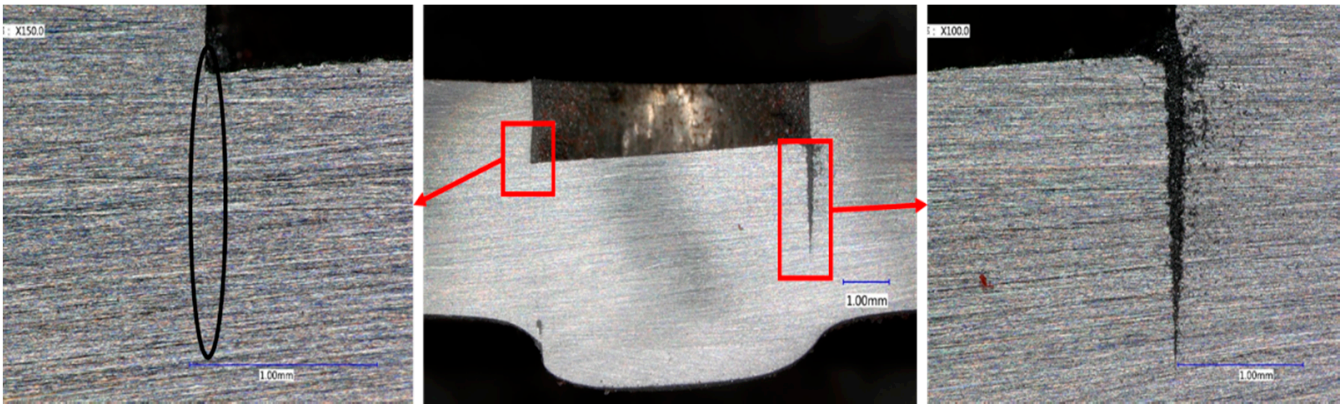

(b)
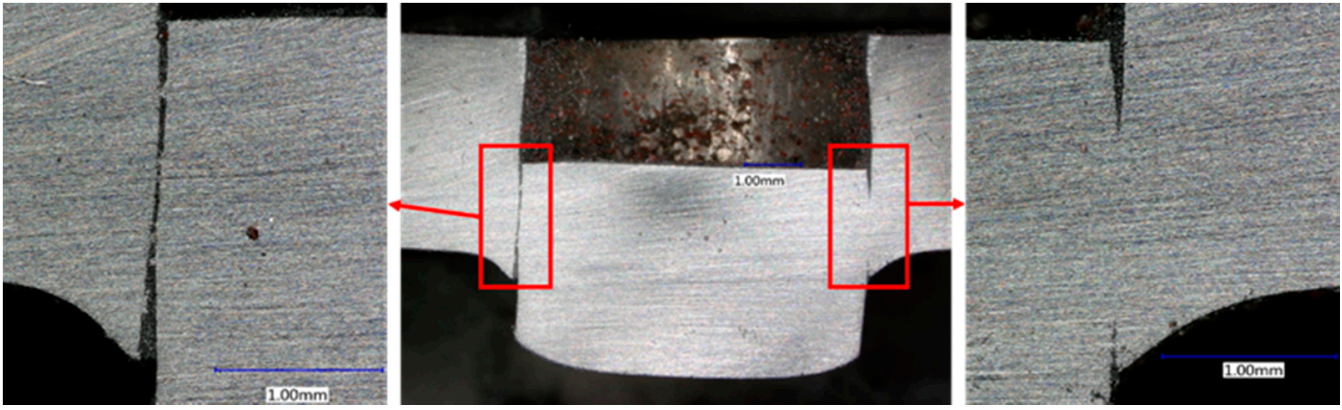

(c)
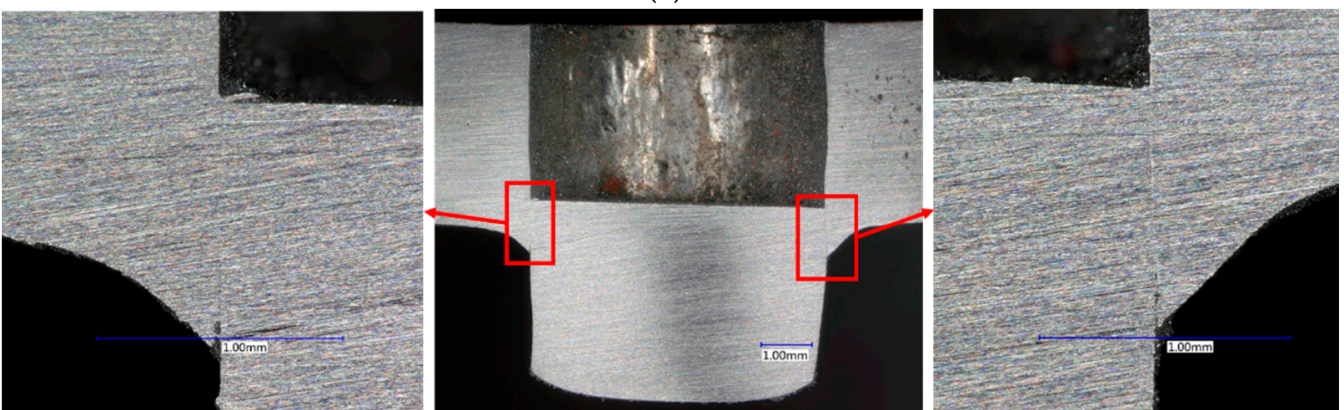

(d)

Figure 6. The fracture patterns of the targets under different impact velocities: (a) $V_{0}=136.6 \mathrm{~m} / \mathrm{s}$. (b) $V_{0}=168.9 \mathrm{~m} / \mathrm{s}$. (c) $V_{0}=170.3 \mathrm{~m} / \mathrm{s}$. (d) $V_{0}=172.9 \mathrm{~m} / \mathrm{s}$.

\section{Numerical Model}

3.1. Material Model

The JC constitutive model [32] was used to characterize the flow stress behavior of Weldox 900 E steel, and is read:

$$
\sigma_{\mathrm{eq}}=\left(A+B \varepsilon_{\mathrm{eq}}^{n}\right)\left(1+C \ln \dot{\varepsilon}_{\mathrm{eq}}^{*}\right)\left(1-T^{*^{m}}\right)
$$

where $A, B$, and $n$ are the yield strength, strain hardening coefficient, and strain hardening index; $C$ is the strain rate hardening coefficient; $m$ is the temperature softening 
coefficient; $\dot{\varepsilon}_{\mathrm{eq}}^{*}$ is the dimensionless strain rate, defined as $\varepsilon_{\mathrm{eq}}^{*}=\varepsilon_{\mathrm{eq}} / \varepsilon_{0}, \varepsilon_{\varepsilon_{\mathrm{eq}}}$ is the current strain rate, $\varepsilon_{\varepsilon_{0}}$ is the reference strain rate; $T^{*}$ is the dimensionless temperature, defined as $T^{*}=\left(T-T_{r}\right) /\left(T_{m}-T_{r}\right), T$ is the current temperature, $T_{r}$ is the reference temperature and $T_{m}$ is the melting temperature.

Metal structures often gather transient physical phenomena such as high temperature, high pressure, and shock wave propagation under the action of impact load [33], so the impact process can be assumed to occur in an adiabatic state, and the temperature rise is estimated by the following formula:

$$
\Delta T=\frac{\chi}{\rho C_{p}} \int \sigma_{e q} \mathrm{~d} \varepsilon_{e q}
$$

where $\rho$ is the material density; $C_{p}$ is the specific heat capacity; $\chi$ is the Taylor-Quincy coefficient with 0.9 [33].

This paper used the element deletion technique to simulate the process of crack expansion during the impact process. The element will be deleted when the damage index of the element reaches 1 . The linear damage accumulation method is used and the damage accumulation index $D$ is defined as:

$$
D=\sum \Delta \varepsilon_{e q} / \varepsilon_{f}
$$

where $\Delta \varepsilon_{\mathrm{eq}}$ is the incremental equivalent plastic strain and $\varepsilon_{f}$ is the fracture strain.

The Lode-independent JC fracture criterion [30], and the Lode-dependent ASCE fracture criterion [34] were used to numerically simulate. The JC fracture criterion is read as:

$$
\varepsilon_{\mathrm{f}}=\left[D_{1}+D_{2} \exp \left(D_{3} \eta\right)\right]\left(1+D_{4} \ln \varepsilon_{e q}^{*}\right)\left(1+D_{5} T^{*}\right)
$$

where $\eta$ is the stress triaxiality, defined as $\eta=\sigma_{\mathrm{m}} / \sigma_{\mathrm{eq}}=\left(\sigma_{1}+\sigma_{2}+\sigma_{3}\right) /\left(3 \sigma_{e q}\right), \sigma_{\mathrm{m}}$ is the hydrostatic pressure, and $\sigma_{1}, \sigma_{2}$ and $\sigma_{3}$ are the first, second, and third principal stresses, respectively; $D_{1}-D_{5}$ is the model parameters.

In this paper, the modified fracture criterion ASCE, as used by JIAO [35], is adopted, and is read:

$$
\varepsilon_{\mathrm{eq}}=\left\{C_{0}+C_{1} \exp \left(C_{2} \eta\right)\left[\cos \left(\frac{\pi}{6} \bar{\theta}\right)^{c_{3}}\right]\right\}\left(1+D_{4} \ln \dot{\varepsilon}_{\mathrm{eq}}^{*}\right)\left(1+D_{5} T^{*}\right)
$$

where $C_{1}, C_{2}, C_{3}$ are model parameters, $\theta$ is the Lode angle, defined as:

$$
\theta=1-\frac{2}{\pi} \mathrm{a} \cos \left[-\frac{27}{2 \sigma_{e q}^{3}}\left(\sigma_{1}-\sigma_{m}\right)\left(\sigma_{2}-\sigma_{m}\right)\left(\sigma_{3}-\sigma_{m}\right)\right]
$$

For the projectiles, a bilinear elastoplastic model and anisotropic hardening strength model without damage [27] were used, and the projectile material constants are listed in Table 2.

Table 2. The material parameters of the blunt projectiles.

\begin{tabular}{ccccc}
\hline $\begin{array}{c}\text { Modulus of } \\
\text { Elasticity }\end{array}$ & Poisson's Ratio & Density & Yield Strength & $\begin{array}{c}\text { Tangent } \\
\text { Modulus }\end{array}$ \\
\hline$E(\mathrm{GPa})$ & $v$ & $\rho\left(\mathrm{kg} / \mathrm{m}^{3}\right)$ & $Y(\mathrm{MPa})$ & $E \mathrm{t}(\mathrm{MPa})$ \\
\hline 204 & 0.33 & 7750 & 1900 & 15,000 \\
\hline
\end{tabular}

In this paper, all the model parameters of Weldox $900 \mathrm{E}$ are quoted from the references [35]. However, for $D_{4}$, a new dynamic tensile test on smooth round bars was performed by using the universal material testing machine. The fracture strain at different strain rates can generally be calculated according to the equation: $\varepsilon_{f}=\ln \left(A_{0} / A_{f}\right)$, where $A_{0}$ is the original cross-sectional area and $A_{f}$ is the area of the fracture area. The strain 
rate parameter $D_{4}=-0.007$ was obtained by fitting the fracture strain of the material at different strain rates, as shown in Figure 7. All material parameters are listed in Table 3.

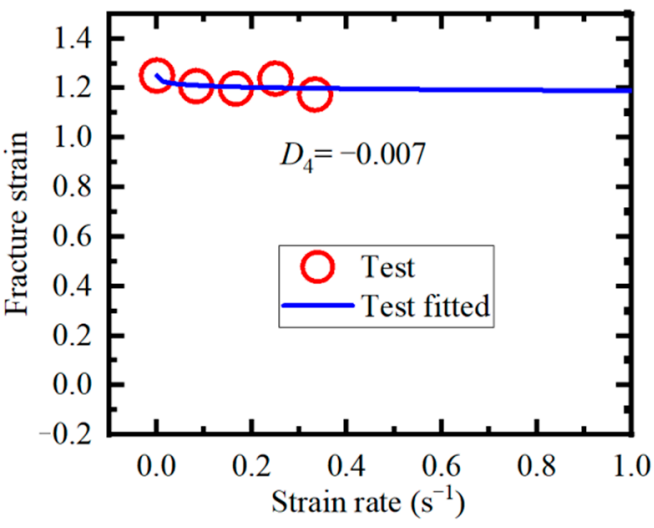

Figure 7. Fracture strain at different strain rates.

Table 3. Summary of Weldox 900 E material parameters.

\begin{tabular}{ccc}
\hline Parameter Name & Notation & Numerical Value \\
\hline Elastic Modulus & $E(\mathrm{GPa})$ & 206 \\
Poisson's ratio & $\mu$ & 0.3 \\
Density & $\rho\left(\mathrm{kg} / \mathrm{m}^{3}\right)$ & 7800 \\
Yield Strength & $A(\mathrm{MPa})$ & 947.48 \\
Strain hardening constant & $B(\mathrm{MPa})$ & 396.5 \\
Strain rate constant & $n$ & 0.383 \\
Reference strain rate & $C$ & 0.023 \\
Thermal softening constant & $\dot{\varepsilon}_{0}\left(\mathrm{~s}^{-1}\right)$ & $4.2^{*} 10^{-4}$ \\
Room temperature & $p$ & 5.931 \\
Melting temperature & $m$ & 2.768 \\
Specific heat & $T_{0}(\mathrm{~K})$ & 293 \\
& $T_{\mathrm{m}}(\mathrm{K})$ & 1800 \\
& $C \mathrm{p}(\mathrm{J} / \mathrm{kg} \mathrm{K})$ & 460 \\
JC & $D_{1}$ & -0.458 \\
& $D_{2}$ & 5.037 \\
& $D_{3}$ & -1.385 \\
& $D_{4}$ & -0.007 \\
ASCE & $D_{5}$ & 7.57 \\
& $D_{6}$ & 2.738 \\
& $C_{1}$ & 1.061 \\
& $C_{2}$ & -1.302 \\
& $C_{3}$ & -7.531 \\
\hline
\end{tabular}

\subsection{Numerical Model and Simulation Results}

A numerical model corresponding to the ballistic test was established in Abaqus/Explicit FE software. From the experimental results, the projectiles penetrated the target plates through the shear plug failure, and there were no other obvious cracks or deformations. Therefore, the axisymmetric model was adopted for saving computing time and computer resources, as shown in Figure 8. The "hard" contact algorithm was used to define the pressure overclosure relationship, or the normal behavior between the projectiles and targets, and the friction coefficient was set to be 0.01 . Both the targets and projectiles were defined as deformable bodies with the CAX4R element type, and the free edge of the target plates completely fixed. The element size of the projectiles was $0.5 \times 0.5 \mathrm{~mm}^{2}$, while the elements in the critical region of crack extension are used with a much finer grid size of $20 \times 20 \mu \mathrm{m}^{2}$ for the targets, as shown in Figure 8. At the same time, in order to investigate the sensitivity of BLV to element size in the numerical simulation, four different element 
sizes $\left(10 \times 10 \mu \mathrm{m}^{2}, 50 \times 50 \mu \mathrm{m}^{2}, 100 \times 100 \mu \mathrm{m}^{2}, 200 \times 200 \mu \mathrm{m}^{2}\right)$ were established in the critical region of crack appearance. In order to save calculation time, the mesh size is larger on both sides of the critical region, because neither cracks nor significant plastic deformations are generated in this part of the region, meaning no significant impact on the calculation results. The irregularly shaped cells only serve as a transition. It should be noted that the type and properties are the same for all elements and are not associated with the element size for the target. The BLV of the numerical simulation is shown in Figure 9, and the corresponding RI model parameters are shown in Table 4.

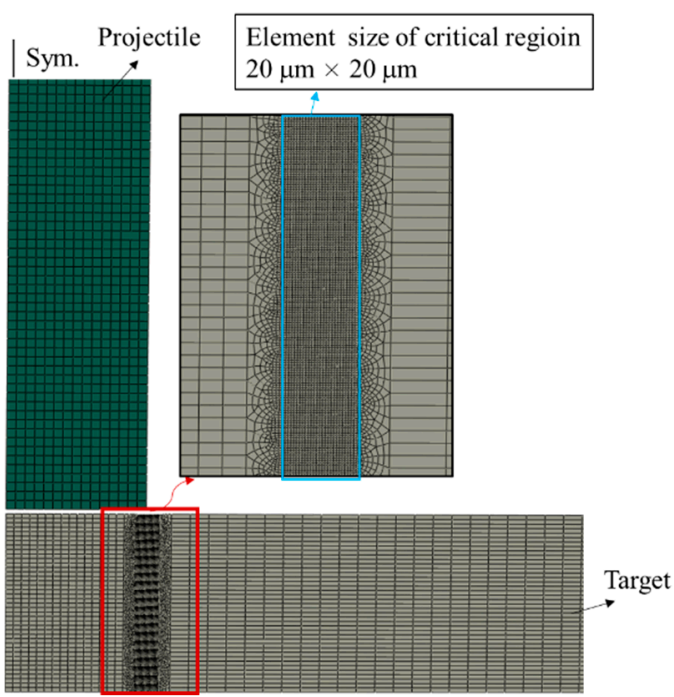

Figure 8. Finite element model with a mesh size of $20 \times 20 \mu \mathrm{m}^{2}$ for the target and the projectile.

The numerical prediction results show that the predicted BLVs by JC or ASCE fracture criterion were in accordance with the test when the element size was $20 \mu \mathrm{m}$. There is no significant difference in BLV predicted by the two, as shown in Figure 9b. This is not in line with the conclusion drawn by JIAO [35]. It can be found that both the BLVs predicted by the JC fracture criterion and the ASCE fracture criterion have significant element size sensitivity, whereby the BLVs increase with the increase in the element size. The BLV was overestimated when the element size was greater than $50 \mu \mathrm{m}$. The BLVs predicted by JC fracture criterion and ASCE fracture criterion were much lower than that of the test when the element size was $10 \mu \mathrm{m}$, as shown in Figures 9 and 10. There was no significant difference for the BLV predicted by the JC or ASCE fracture criterion when the mesh size was the same. This seems to indicate that the introduction of the Lode angle into the fracture criterion has essentially no effect on the BLV prediction. Figure 11 shows the final fracture behavior of the target with $20 \mu \mathrm{m}$ element size, predicted by the JC and the ASCE fracture criterion when the impact velocity was slightly lower, slightly higher, and much higher than the BLV. Both of them predicted pure shear plug, and there was no significant difference, which is similar to the experimental observations. The above phenomenon also occurs when other element sizes were used. In order to save space, this paper does not show it. 


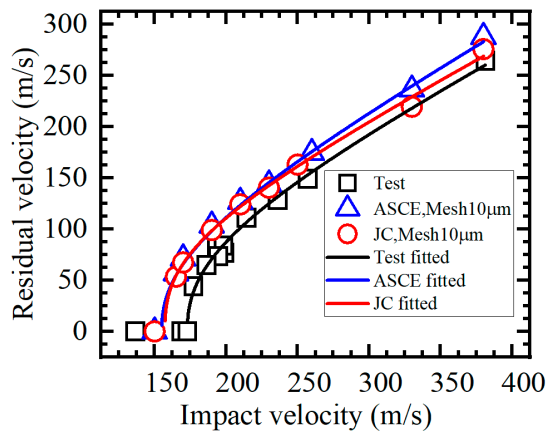

(a)

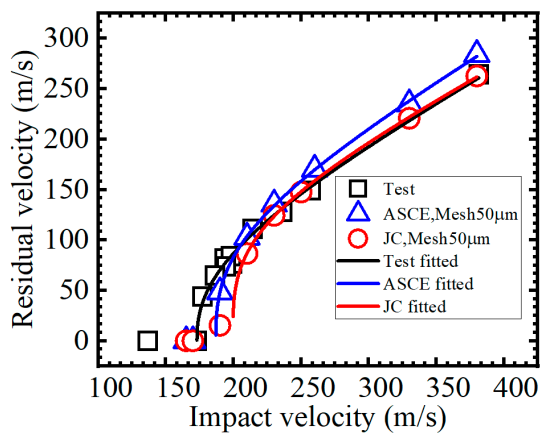

(c)

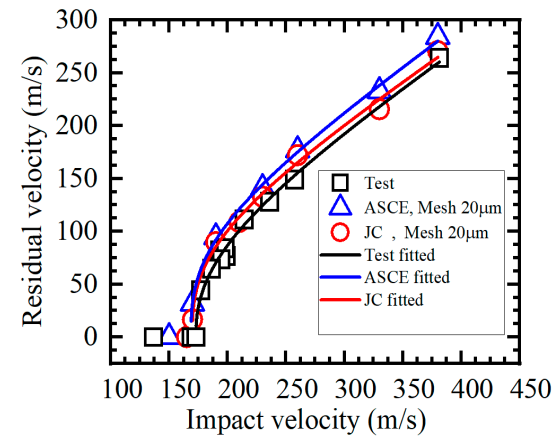

(b)

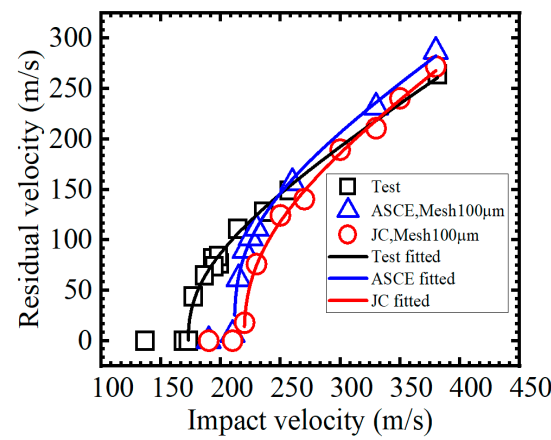

(d)

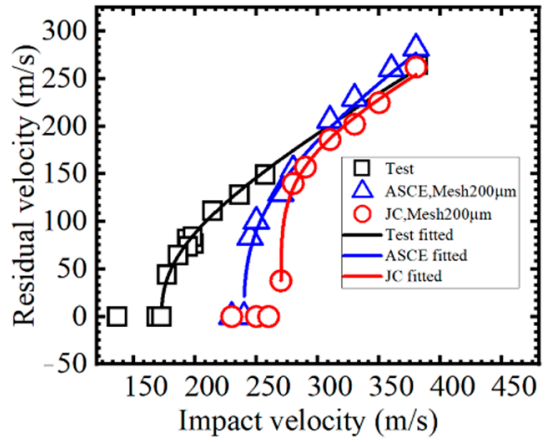

(e)

Figure 9. Numerical simulation results of ballistic limit velocity with different element sizes. (a) Mesh size $10 \mu \mathrm{m}$. (b) Mesh size $20 \mu \mathrm{m}$. (c) Mesh size $50 \mu \mathrm{m}$. (d) Mesh size $100 \mu \mathrm{m}$. (e) Mesh size $200 \mu \mathrm{m}$.

Table 4. Summary of BLVs and Recht-Ipson model parameters under different element sizes.

\begin{tabular}{|c|c|c|c|c|c|c|}
\hline Results & Mesh Size & Fracture criterion & $a$ & $p$ & $V_{b l}(\mathrm{~m} / \mathrm{s})$ & $V_{b l}$ \\
\hline \multirow[t]{5}{*}{ Test result } & & & 0.73 & 2.57 & 172.93 & \\
\hline & \multirow{2}{*}{$10 \mu \mathrm{m}$} & $\mathrm{JC}$ & 0.73 & 2.65 & 157.26 & $9.21 \%$ \\
\hline & & ASCE & 0.78 & 0.32 & 155 & $9.29 \%$ \\
\hline & \multirow{2}{*}{$20 \mu \mathrm{m}$} & $\mathrm{JC}$ & 0.73 & 2.75 & 169.74 & $1.84 \%$ \\
\hline & & ASCE & 0.76 & 2.76 & 168.71 & $2.44 \%$ \\
\hline \multirow{6}{*}{ FE result } & \multirow{2}{*}{$50 \mu \mathrm{m}$} & $\mathrm{JC}$ & 0.71 & 3.37 & 199 & $15.07 \%$ \\
\hline & & ASCE & 0.86 & 2.48 & 187 & $8.15 \%$ \\
\hline & \multirow{2}{*}{$100 \mu \mathrm{m}$} & $\mathrm{JC}$ & 0.79 & 2.49 & 219.65 & $26.6 \%$ \\
\hline & & ASCE & 0.79 & 3.06 & 211.46 & $22.28 \%$ \\
\hline & \multirow{2}{*}{$200 \mu \mathrm{m}$} & $\mathrm{JC}$ & 0.69 & 4.89 & 269.97 & $56.11 \%$ \\
\hline & & ASCE & 0.82 & 2.71 & 240 & $38.78 \%$ \\
\hline
\end{tabular}




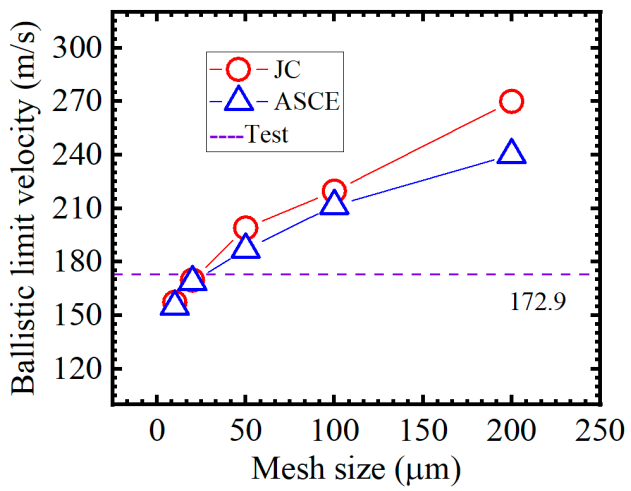

Figure 10. Mesh size sensitivity of BLV predicted using JC fracture criterion and ASCE fracture criterion.

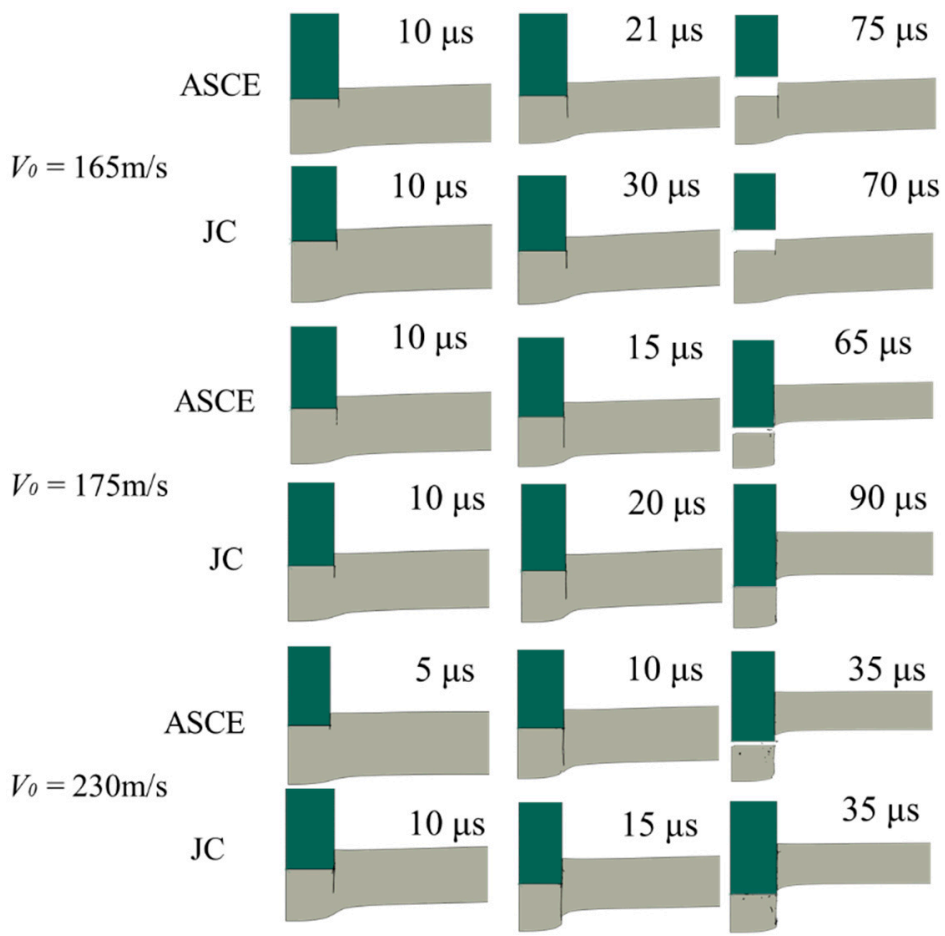

Figure 11. Fracture behavior of targets with an element size of $20 \mu \mathrm{m}$.

\section{Discussion}

In the previous section, the numerical calculations of ballistic tests of the Weldox $900 \mathrm{E}$ target were performed by using ASCE and JC fracture criteria. The results have shown that the Lode-dependent fracture criterion and the Lode-independent fracture criterion predicted essentially the same fracture behavior and BLVs of the targets. This contradicts the conclusions of some public documents [20]. Xiao et al. [30] attributed it to the higher temperature during the impact.

To further explain the possible reasons for this phenomenon, Figure 12 shows the history variables of some elements on the fracture path in the model with an element size of $20 \mu \mathrm{m}$, and an initial velocity of $175 \mathrm{~m} / \mathrm{s}$. The location of the elements for extracting variables is shown in Figure 12a. It can be found that the PEEQ predicted by the ASCE fracture criterion reaches a high level, but the damage accumulation is at a relatively low level from Figure 12b,d, which means high strain corresponds to low damage. This is due to the large amount of plastic work accumulated by these elements in a very short period of time, due to the large deformation that occurs during the impact. This then results in a rapid increase in the temperature of these elements, which causes a smaller accumulation of damage, as shown in Figure 12c. The trends of stress triaxiality and Lode angle with 
time predicted by ASCE fracture criteria was extracted, as shown in Figure 12e,f. It can be seen in the above section that the stress state variables predicted by the two fracture criteria are not significantly different. This indicates that the Lode parameter does not show a significant effect when the lode parameter was introduced into the fracture criterion to predict the fracture behavior and BLV of the target. The authors believe that the higher temperature rise effect in the process of shear plugging is an important reason for this phenomenon. Because the thermal softening effect will overcome the effect of the strainhardening effect [36] and causes greater plastic deformation of the material. Therefore, the temperature change trend of the above-mentioned elements during the impact of the projectile was extracted, as shown in Figure 12c. It can be seen from the figure that the temperature predicted by ASCE fracture criteria has reached a considerable level, even for the element whose damage factor reaches 1 in a short period of time. According to the fracture locus predicted by the JC and ASCE fracture criteria, the fracture strain predicted by ASCE is significantly lower than that predicted by JC when the elements failed by shear, as shown in Figure 13. However, a higher temperature will mask this phenomenon, because high temperature will cause high PEEQ, and it will be deleted when the PEEQ of the element reaches a certain value, even if the damage factor of the element is less than 1. In addition, higher temperatures will make the stress state of the elements deceptive, so that the stress states of the elements on the shear fracture path predicted by the two fracture criteria are not significantly different. However, it is very difficult to accurately obtain the adiabatic temperature rise in the fracture region of the target plate during ballistic impact, and this remains a pressing challenge.

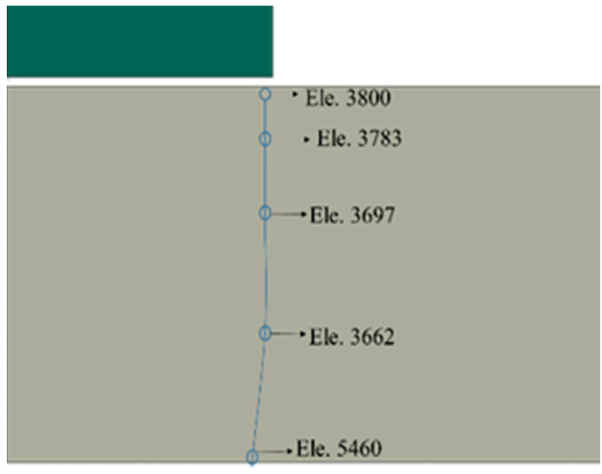

(a)

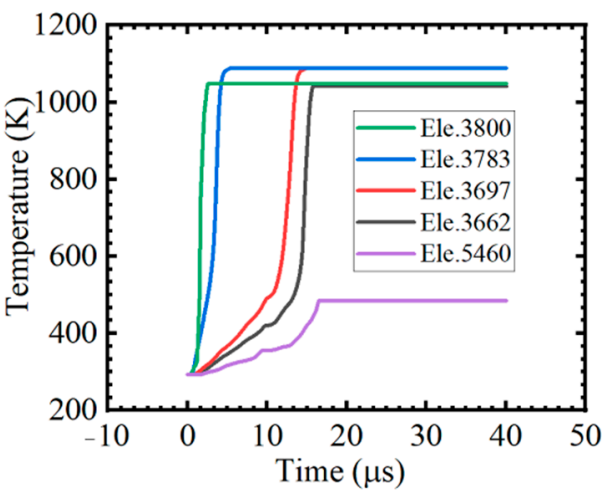

(c)

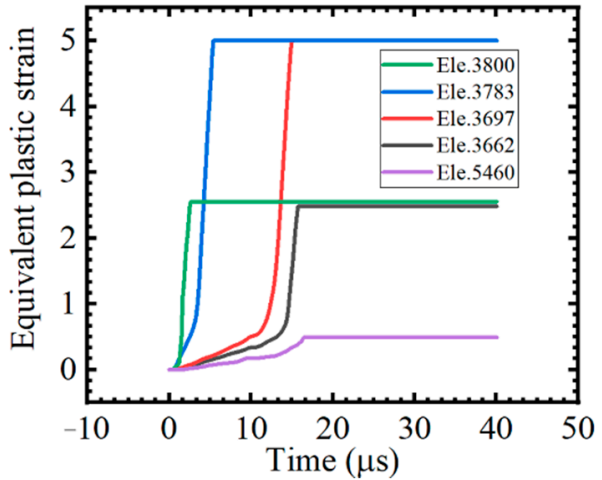

(b)

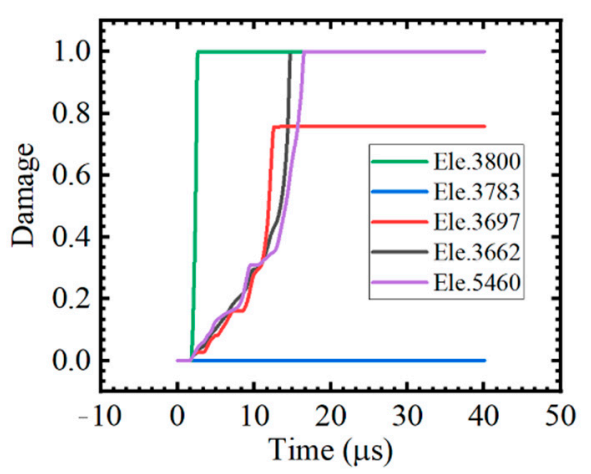

(d)

Figure 12. Cont. 


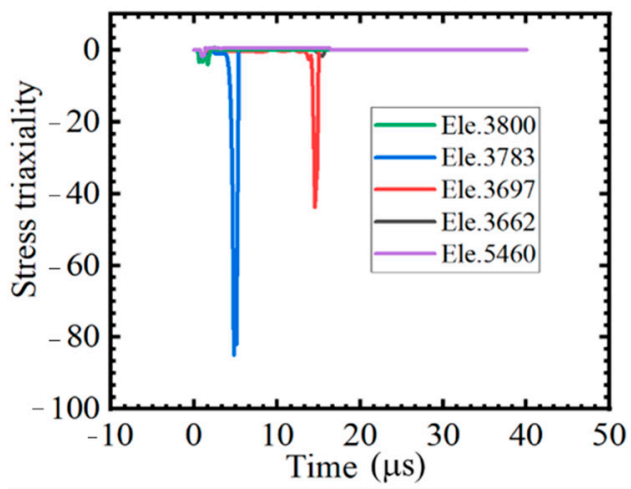

(e)

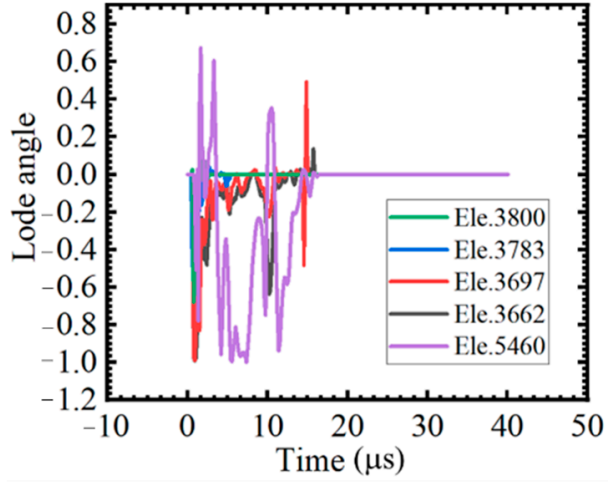

(f)

Figure 12. Changes in some history variables over time. (a) Different element locations. (b) PEEQ. (c) Temperature. (d) Damage. (e) Stress triaxiality. (f) Lode angle.

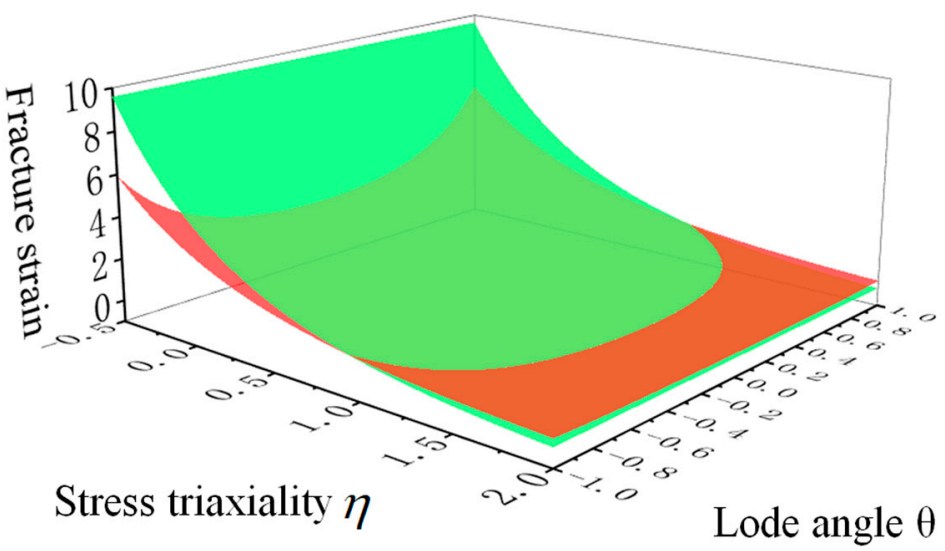

Figure 13. Comparison of the ductility of two fracture criteria under principal stress state region.

Xiao and the co-authors also found this phenomenon when they used the Lodedependent fracture criterion to predict the ballistic resistance of Weldox 700 E steel [30], but not for the 2024 aluminum alloy [20]. This may have an important relationship with the ductility of the material, because the ductility of Weldox $700 \mathrm{E}$ steel and Weldox $900 \mathrm{E}$ steel is much higher than that of 2024 aluminum alloy, as shown in Figure 14. For this reason, Xiao et al. [30] investigated the influence of ductility on the ballistic resistance of Weldox 700 E steel by changing the ductility coefficient. The result shows that the BLV predicted by the Lode-dependent MMC fracture criterion is more sensitive to the ductility, consult this literature for details. In addition, the fracture trajectories of the two steels essentially overlapped, indicating that the fracture parameters were similar, but the higher strength Weldox 900 E steel (25.6\% higher yield strength than Weldox $700 \mathrm{E}$ ) did not exhibit a higher BLV, but instead was 9.3\% lower than Weldox 700 E, as shown in Figure 15, which was surprising. The BLV of Weldox $700 \mathrm{E}$ steel remains generally high for the same mesh size, which seems to reflect the real situation, but the numerical simulation results are still a conservative estimate considering the complex influencing factors, such as strain rate effect and temperature effect. 


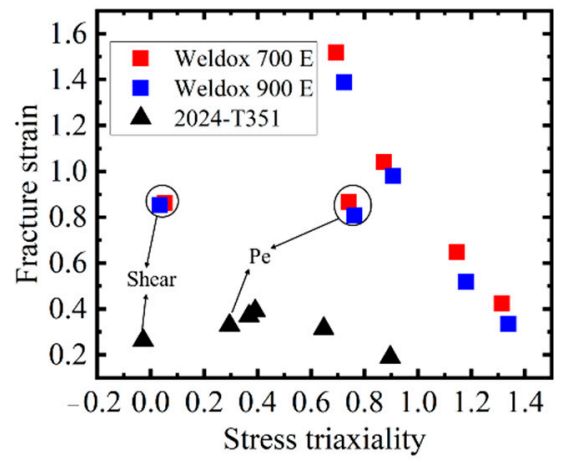

Figure 14. Comparison of the ductility of three metal materials.

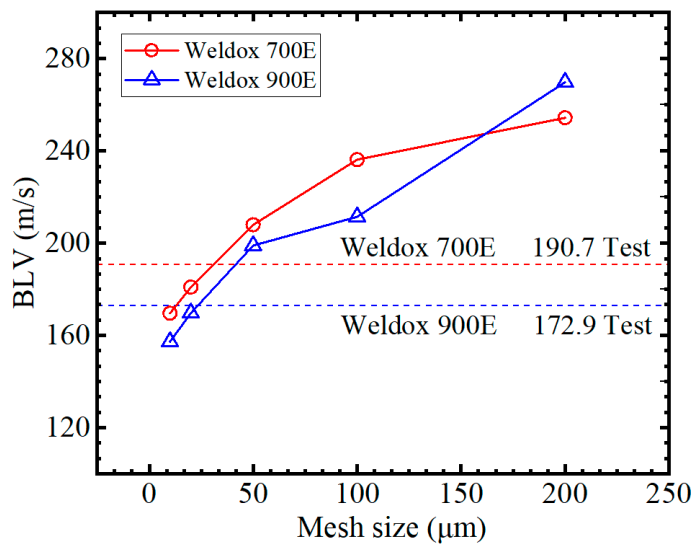

Figure 15. Curves of BLV with mesh size for Weldox $700 \mathrm{E}$ [30] and Weldox $900 \mathrm{E}$ steels calculated using the JC fracture criterion.

\section{Conclusions}

To demonstrate the necessity of the introduction of Lode parameter into the fracture criterion to predict the ballistic resistance of high-strength steel targets, the ballistic tests were conducted on $4 \mathrm{~mm}$ thick Weldox $900 \mathrm{E}$ steel targets. The fracture behavior and BLV of the targets were obtained. Subsequently, the parallel 2D axisymmetric model was established in Abaqus/Explicit software and the Lode-independent JC and Lode-dependent ASCE fracture criterion were incorporated into the FE model for numerical simulation. The following conclusions were obtained from the comparative analysis of the experimental and numerical simulation results:

1. The fracture locus of Weldox $900 \mathrm{E}$ high-strength steel is obviously related to Lode angle;

2. The introduction of Lode parameter into the fracture criterion does not improve the prediction accuracy of the BLV. Additionally, the BLV of the Weldox $900 \mathrm{E}$ highstrength steel has a high mesh size sensitivity;

3. For Weldox $900 \mathrm{E}$ high-strength steel, the adiabatic temperature rise effect is very obvious in ballistic tests. This rapid temperature rise will seriously soften the elements on the fracture path, resulting in larger plastic strains, which will cover the influence mechanism of the Lode parameter on fracture strain.

Author Contributions: Y.S.: Investigation, Conceptualization, Methodology, Formal analysis, Validation Writing-review and editing. A.H.: Investigation, Methodology, Formal analysis, Validation. T.D.: Investigation, Validation. X.X.: Funding acquisition, Project administration, Supervision, Resources, Investigation, Experiment, Formal analysis, Validation. B.J.: Investigation, Methodology, Validation. All authors have read and agreed to the published version of the manuscript. 
Funding: This research was funded by the Science and Technology Bureau of Nanyang (No.: JCQY006), the Education Department of Henan Province (No.: 2019GGJS233), and the National Natural Sci-ence Foundation of China (No.: 11502120).

Data Availability Statement: All data are presented in this research.

Conflicts of Interest: The authors declare no conflict of interest.

\section{References}

1. Moćko, W.; Janiszewski, J.; Radziejewska, J.; Grąza, M. Analysis of deformation history and damage initiation for 6082-T6 aluminium alloy loaded at classic and symmetric Taylor impact test conditions. Int. J. Impact Eng. 2015, 75, 203-213. [CrossRef]

2. Dey, S.; Børvik, T.; Hopperstad, O.; Leinum, J.; Langseth, M. The effect of target strength on the perforation of steel plates using three different projectile nose shapes. Int. J. Impact Eng. 2004, 30, 1005-1038. [CrossRef]

3. Balos, S.; Howard, D.; Brezulianu, A.; Zlatanović, D.L. Perforated Plate for Ballistic Protection-A Review. Metals 2021, 11, 526 [CrossRef]

4. Zochowski, P.; Bajkowski, M.; Grygoruk, R.; Magier, M.; Burian, W.; Pyka, D.; Bocian, M.; Jamroziak, K. Ballistic Impact Resistance of Bulletproof Vest Inserts Containing Printed Titanium Structures. Metals 2021, 11, 225. [CrossRef]

5. Børvik, T.; Langseth, M.; Hopperstad, O.; Malo, K.A. Ballistic penetration of steel plates. Int. J. Impact Eng. 1999, 22, 855-886. [CrossRef]

6. Dey, S.; Børvik, T.; Hopperstad, O.; Langseth, M. On the influence of fracture criterion in projectile impact of steel plates. Comput Mater. Sci. 2006, 38, 176-191. [CrossRef]

7. Zhang, W.; Xiao, X.K.; Guo, Z.T.; Mu, Z.C.; Wei, G. Investigation on the Ballistic Resistance of Double-Layered A3 Steel Targets Against Blunt Projectile Impact. Chin. J. High Press. Phys. 2012, 26, 163-170. (In Chinese) [CrossRef]

8. Rodríguez-Millán, M.; Díaz-Álvarez, A.; Bernier, R.; Miguélez, M.H.; Loya, J.A.; Millán, R. Loya Experimental and Numerical Analysis of Conical Projectile Impact on Inconel 718 Plates. Metals 2019, 9, 638. [CrossRef]

9. Sima, Y.Z.; Xiao, X.K.; Wang, Y.P.; Zhang, W. Tests and numerical simulation for anti- penetrating behavior of a high strength 7A04- T6 aluminium alloy plate against a blunt projectile's impact. J. Vib. Shock. 2017, 36, 1-8. (In Chinese) [CrossRef]

10. Xiao, X.; Zhang, W.; Wei, G.; Mu, Z.; Guo, Z. Experimental and numerical investigation on the deformation and failure behavior in the Taylor test. Mater. Des. 2011, 32, 2663-2674. [CrossRef]

11. Xiao, X.; Pan, H.; Bai, Y.; Lou, Y.; Chen, L. Application of Lode dependent fracture criterion in predicting fracture of 6061-T6511H aluminium alloy Taylor rods. J. Vib. Shock. 2018, 37, 142-149. (In Chinese) [CrossRef]

12. Zhang, W.; Xiao, X.K.; Wei, G. Constitutive relation and fracture model of 7A04 aluminum alloy. Explos. Shock. Waves 2011, 31, 81-87. (In Chinese)

13. Zhang, W.; Xiao, X.-K.; Wei, G.; Guo, Z. Evaluation of five fracture models in Taylor impact fracture. Am. Phys. Soc. 2012, 1426, 1125-1128. [CrossRef]

14. Xiao, X.K.; Mu, Z.C.; Pan, H.; Lou, Y.S. Effect of the Lode parameter in predicting shear cracking of 2024-T351 aluminum alloy Taylor rods. Int. J. Impact Eng. 2018, 120, 185-201. [CrossRef]

15. Jia, Y.; Bai, Y. Ductile fracture prediction for metal sheets using all-strain-based anisotropic eMMC model. Int. J. Mech. Sci. 2016, 115-116, 516-531. [CrossRef]

16. Pan, H.; Liu, J.; Choi, Y.; Xu, C.; Bai, Y.; Atkins, T. Zones of material separation in simulations of cutting. Int. J. Mech. Sci. 2016, 115-116, 262-279. [CrossRef]

17. Shabahang, S.; Tao, G.; Kaufman, J.J.; Qiao, Y.; Wei, L.; Bouchenot, T.; Gordon, A.P.; Fink, Y.; Bai, Y.; Hoy, R.S.; et al. Controlled fragmentation of multimaterial fibers and films via polymer cold-drawing. Nature 2016, 534, 529-533. [CrossRef]

18. Teng, X.; Wierzbicki, T.; Hiermaier, S.; Rohr, I. Numerical prediction of fracture in the Taylor test. Int. J. Solids Struct. 2005, 42, 2929-2948. [CrossRef]

19. Teng, X.; Wierzbicki, T. Evaluation of six fracture models in high velocity perforation. Eng. Fract. Mech. 2006, 73, 1653-1678. [CrossRef]

20. Xiao, X.; Pan, H.; Bai, Y.; Lou, Y.; Chen, L. Application of the modified Mohr-Coulomb fracture criterion in predicting the ballistic resistance of 2024-T351 aluminum alloy plates impacted by blunt projectiles. Int. J. Impact Eng. 2018, 123, 26-37. [CrossRef]

21. Gilioli, A.; Manes, A.; Giglio, M.; Wierzbicki, T. Predicting ballistic impact failure of aluminium 6061-T6 with the rate-independent Bao-Wierzbicki fracture model. Int. J. Impact Eng. 2015, 76, 207-220. [CrossRef]

22. Wierzbicki, T.; Bao, Y.; Lee, Y.-W.; Bai, Y. Calibration and evaluation of seven fracture models. Int. J. Mech. Sci. 2005, 47, 719-743. [CrossRef]

23. Xue, L. Damage accumulation and fracture initiation in uncracked ductile solids subject to triaxial loading. Int. J. Solids Struct. 2007, 44, 5163-5181. [CrossRef]

24. Bai, Y.; Wierzbicki, T. A new model of metal plasticity and fracture with pressure and Lode dependence. Int. J. Plast. 2008, 24, 1071-1096. [CrossRef]

25. Johnson, G.R.; Chocron, S.; Anderson, C.E., Jr.; Beissel, S.R.; Holmquist, T.J. Effect of the third invariant on strength and failure for 10 metals. In Proceedings of the 27th International Symposiumon Ballistics, Freiburg, Germany, 22-26 April 2013 ; pp. 1-12. 
26. Yoon, J.W.; Lou, Y.; Yoon, J.; Glazoff, M.V. Asymmetric yield function based on the stress invariants for pressure sensitive metals. Int. J. Plast. 2014, 56, 184-202. [CrossRef]

27. Li, Y.; Du, Z.; Wu, W.; Zhu, H.; Zhang, L.; Zhang, W. Dynamic failure criterion of ship-build metal based on stress trixiality and Lode parameter. J. Harbin Inst. Technol. 2017, 49, 153-157. (In Chinese) [CrossRef]

28. Deng, Y.; Zhang, Y.; Xiao, X.; Hu, A.; Wu, H.; Xiong, J. Experimental and numerical study on the ballistic impact behavior of 6061-T651 aluminum alloy thick plates against blunt-nosed projectiles. Int. J. Impact Eng. 2020, 144, 103659. [CrossRef]

29. Xiao, X.; Chen, L.; Du, T. Tests and numerical simulation for shear plugging of 7075-T651 aluminum alloy targets. J. Vib. Shock. 2019, 38, 51-58. [CrossRef]

30. Xiao, X.; Wang, Y.; Vershinin, V.V.; Chen, L.; Lou, Y. Effect of Lode angle in predicting the ballistic resistance of Weldox $700 \mathrm{E}$ steel plates struck by blunt projectiles. Int. J. Impact Eng. 2019, 128, 46-71. [CrossRef]

31. Recht, R.F.; Ipson, T.W. Ballistic Perforation Dynamics. J. Appl. Mech. 1963, 30, 384-390. [CrossRef]

32. Johnson, G.R.; Cook, W.H. A constitutive model and data for metals subjected to large strains, high strain rates and high temperatures. In Proceedings of the seventh inter-national symposium on ballistics, The Hague, The Netherlands, 19-21 April 1983; pp. 541-547.

33. Knysh, P.; Korkolis, Y.P. Determination of the fraction of plastic work converted into heat in metals. Mech. Mater. 2015, 86, 71-80. [CrossRef]

34. Wen, H.; Mahmoud, H. New model for ductile fracture of metal alloys. I: Monotonic loading. J. Eng. Mech. 2016, 142, 04015088. [CrossRef]

35. Jiao, B. Research and Application of Weldox 900 E Steel Constitutive Model and Fracture Criterion. Master's Thesis, Zhengzhou University, Zhengzhou, Henan, 1 May 2019. (In Chinese).

36. Lindholm, U.S.; Johnson, G.R. Strain rate effects in metals at large shear strains. In Proceedings of the 29th Sagamore Army Materials Conference entitled Material Behaviour Under High Stress and Ultrahigh Loading Rates, New York, NY, USA, 19-23 July 1982. 